\title{
Humor e violência no Tuíter durante os protestos pelo impeachment de Dilma Rousseff
}

\author{
Anelisa Maradei \\ Universidade Metodista de São Paulo / Universidade Beira Interior \\ E-mail: anedamaradei.com.br
}

\begin{abstract}
Resumo
O presente artigo tem por objetivo analisar a comunicação que se estabeleceu entre os atores sociais pelo Tuíter durante os protestos pelo impeachment da ex-presidente do Brasil, Dilma Rousseff. Foram analisados 250 posts, categorizados buscando explorar aspectos como violência, humor, gênero dos atores sociais, posição adotada (contra ou a favor do

execução da pesquisa e de análise de conteúdo, qualitativa e quantitativa do material. Percebe-se que há amplo uso do humor para as manifestações de violência que se processam na rede social online. Há também uma ligeira predominância de posts com conteúdo ligado ao humor em relação aos posts com conteúdo envolvendo violência.
\end{abstract} governo). Utilizamos de revisão bibliográfica para a

Palavras-chave: Tuíter; redes sociais online; impeachment; comunicação; protestos.

\begin{abstract}
This article aims to analyze the communication established among the social actors through twitter during the protests for the impeachment of Brazil's former president, Dilma Rousseff. A total of 250 posts were analyzed, categorized to search aspects such as violence, humor, gender of the social actors, position adopted (against or in favor of the government). We

and analysis of qualitative and quantitative content of the material. It is noticed that there is ample use of the humor for violence manifestations that are processed in the digital network. There is also a higher prevalence of posts with content linked to humor and irony compared to posts with content involving violence.
\end{abstract} used a bibliographic review to perform the research

Keywords: Twitter; online social network; impeachment; communication; protests.

Data de submissão: 31/05/2017. Data de aprovação: 30/06/2017.

A Revista Estudos em Comunicação é financiada por Fundos FEDER através do Programa Operacional Factores de Competitividade - COMPETE e por Fundos Nacionais através da FCT - Fundação para a Ciência e a Tecnologia no âmbito do projeto Comunicação, Filosofia e Humanidades (LabCom.IFP) UID/CCI/00661/2013.

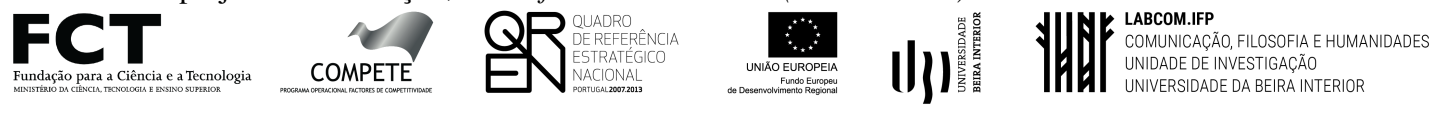




\section{Introdução}

$\mathrm{O}$

PRESENTE artigo tem por objetivo analisar a comunicação que se estabeleceu entre os atores sociais pelo Tuíter durante o horário das manifestações de março de 2016, no Brasil, pelo impeachment da ex-presidente Dilma Rousseff. A então presidente, que governava o País pelo Partido dos Trabalhadores, após denúncias de corrupção em seu governo, viu a nação se mobilizar por sua saída da presidência e sua popularidade desabar, o que culminaria em seu impeachment em 31 de agosto de 2016.

Os protestos contra o governo de Dilma, que ocorreram em todo território nacional, se centraram em manifestações contra sua administração e, também, na defesa dos avanços da Operação Lava Jato ${ }^{1}$, que promove investigações sobre escândalo de desvios financeiros e corrupção na Petrobrás. A pesquisa que aqui apresentamos tem por base a observação da comunicação que ocorreu durante os protestos entre os atores sociais pelo Tuíter, no dia 13 de março de 2016, das 15 às 18 horas. Partimos de 250 posts, coletados por busca semântica, a partir das hashtags \#globogolpista, \#vemprarua, \#acordabrasil, \#protestobr, \#protestosp, \#mudabrasil.

Ressaltamos que nossa amostragem procurou mesclar os horários de forma a não interromper o debate e, ao mesmo tempo, não criar um discurso recorrente, em uma média de 30 a 40 posts por bloco de horário. Ou seja, fizemos a coleta dos posts evitando uma projeção dos ecos que costumam ser habituais entre curtos intervalos de comunicação. Para o estudo, utilizamos de uma análise de rede, combinada com análise do conteúdo dos posts, que foram categorizados quantitativamente.

A análise em profundidade dos posts, entretanto, nos permitiu avançar para uma observação qualitativa em torno dos debates dos atores sociais durante o processo, na medida em que as postagens foram abertas uma a uma e categorizadas de forma a observar:

1. A questão do apelo irônico das mensagens;

2. Aspectos violentos encontrados nos discursos e nas imagens;

3. Gênero dos atores presentes na rede;

4. Posts contra e a favor do governo (seja o impeachment ou a operação Lava Jato);

5. E, por fim, observamos como estiveram distribuídos os atores sociais em termos geográficos, dentro das possibilidades dadas pela ferramenta de busca, pois, muitas vezes, por questões de configuração estabelecida pelo usuário, tal identificação não é possível.

Bardin (2010, p.38) define a análise de conteúdo como "uma técnica de investigação que tem por finalidade a descrição objetiva, sistemática e quantitativa do conteúdo manifesto na comunicação". Embora tenhamos percorrido uma das etapas dentro dessa perspectiva, nossa metodologia associou também a visão individualizada do comportamento dos atores na rede. Assim, consideramos que nos apropriamos de uma metodologia híbrida, que pode ser considerada também qualitativa. Associamos duas formas de investigação pois, como sustenta (W. Goode \& P. K. Hatt):

1. A Operação Lava Jato é a maior investigação sobre corrupção conduzida até hoje no Brasil. Ela começou investigando uma rede de doleiros que atuavam em vários Estados e descobriu a existência de um vasto esquema de corrupção na Petrobras, envolvendo políticos de vários partidos e as maiores empreiteiras do País. 
A pesquisa moderna deve rejeitar como uma falsa dicotomia a separação entre estudos "qualitativos" e "quatitativos", ou entre ponto de vista "estatístico" e "não estatístico". Além disso, não importa quão precisas sejam as medidas, o que é medido continua a ser uma qualidade (W. Goode \& P. K. Hatt, 1973, p.39).

A pesquisa foi complementada por revisão bibliográfica, que teve como principal norteador Castells $(2013,2015)$, que explora o conceito de autocomunicação ${ }^{2}$ como forma de empoderamento dos atores sociais. Tal conceito foi aplicado às práticas comunicativas que se estabelecem durante os movimentos sociais, especialmente no que tange ao uso de memes, humor e violência como forma de expressão.

\section{Novas formas de se manifestar}

As políticas neoliberais dos anos 90, bem como a globalização, aprofundaram a marginalização, o desemprego e os conflitos sociais, gerando condições para "uma forte cultura urbana do protesto e a reorganização dos movimentos de reivindicação social" (Vizer 2007, p.43), que hoje presenciamos em nossa sociedade. Para Bauman (2016), o que está acontecendo é um "colapso da confiança". Na percepção do sociólogo, há a "crença de que os líderes não só são corruptos ou estúpidos, mas também incapazes". Para atuar nesse cenário, é necessário poder e política: "poder: ser capaz de fazer coisas; e política: a habilidade de decidir quais são as coisas que têm que ser feitas".

A América Latina, por exemplo, apesar da implantação de sistemas democráticos em muitos países nos últimos anos, vem sendo atingida por problemas de dívida externa, inflação, corrupção por parte dos governantes, concentração extrema de riquezas, violência, o que tem levado ao aprofundamento da desigualdade social. Como bem ponderou Freire, os discursos neoliberais não tiveram êxito em " [...] acabar com as classes sociais e decretar a inexistência de interesses diferentes entre elas, bem como não têm força para acabar com os conflitos e lutas entre elas. $\mathrm{O}$ que acontece é que a luta é uma categoria histórica e social (Freire, 1992, p. 21).

De um Estado-nação de base agrícola, migramos, no Brasil, para uma realidade urbana nos últimos anos, que tem concentrado grupos sociais muito distintos, "aproximando o que antes era disperso, num processo que se desenvolveu na América Latina em menos de meio século", Gómez de la Torre e Reichert (2011, p.151). Como bem observam os autores, o intercâmbio fomentado pelo desenvolvimento dos centros urbanos e das tecnologias da informação e da comunicação ganha força em processos que envolvem exclusão, desigualdade e inclusão das diferenças.

$\mathrm{E}$, é nesse contexto, que nos propomos a desenvolver a observação sobre os debates nas redes sociais online durante os movimentos sociais da contemporaneidade. Evidentemente, nosso olhar se projeta para o presente, para nosso objeto de estudo, cujo enquadramento está ligado às manifestações que se dão sob o impacto das tecnologias da informação e comunicação, com forte auxílio mobilizador e de propagação pela internet.

2. Autocomunicação ocorre quando a "produção da mensagem é decidida de modo autônomo pelo remetente, a designação do receptor é auto direcionada e a recuperação de mensagens e das redes de comunicação é autosseleciona" (Castells, 2013, p.12). 
Dessa forma, embora as demandas dos atores sociais se reconfigurem através dos tempos e novas expectativas sejam incorporadas ao repertório deliberativo, notamos que os movimentos sociais permanecem vivos em diferentes momentos da história, seja no Brasil, seja em nível mundial, ainda que tomem formas diversificadas. Toda nossa análise, é importante que se esclareça, parte de observação que tem como parâmetro a perspectiva baseada na interação entre poder e contrapoder proposta por Castells (2015). É a partir das relações de poder que se estabelecem na sociedade brasileira que observamos os movimentos sociais.

Para Castells, o poder vem das instituições e o contrapoder da sociedade civil. O poder é "o processo mais fundamental na sociedade, já que a sociedade é definida em torno de valores e instituições e o que é valorizado e institucionalizado é definido pelas relações de poder" (Castells, 2015, p. 57). A Teoria fundamentada no poder apresentada por Castells na obra O Poder da Comunicação (2015) parte da premissa de que as relações de poder são constitutivas da sociedade e que os sistemas políticos na atualidade estão mergulhados na referida crise de confiança, da qual também nos fala Bauman.

Entretanto, para o autor, há uma crise de confiança que teria sido ampliada pela intercomunicação individual, que deu a possibilidade aos atores sociais de desafiarem o Estado e as instituições em geral. Esse desafio, como veremos no decorrer do nosso trabalho, é feito em grande escala, nos dias de hoje, por meio de novas formas de expressão, utilizando-se, nas redes sociais, por exemplo, do humor e de discursos que incorporam violência para protestar.

Porém, se os processos de comunicação são decisivos para estruturar as interações durante os protestos, Castells (2015) não percebe o uso das tecnologias na comunicação dos atores sociais como determinante. Para ele, vale lembrar, os movimentos de protesto são processos mais complexos e ancorados nas relações sociais, perspectiva com a qual nos alinhamos. Nessa direção, Barbero também ressalta que a tecnologia não é um simples fato material em nossa sociedade, mas que tem dimensões simbólicas. Nesse sentido, estabelecemos nossas observações, e partimos para a exploração das formas de expressão contendo humor e violência no tuíter.

Mas, em contrapartida, se, por um lado Castells não coloca a internet como determinante no processo de tomada de poder, ele também não a neutraliza, e dá a ela um importante papel para desafiar as instituições. Os movimentos sociais fundamentados nas redes sociais online seriam, hoje, componentes essenciais da ação coletiva dentro dessa linha de percepção. As pessoas só podem desafiar a dominação conectando-se entre si, compartilhando sua indignação, construindo projetos e caminhos alternativos para as sociedades onde estão inseridas e, uma das possiblidades mais importantes, está no uso da internet.

O uso da internet, e evidentemente das redes sociais online, amplia o debate por meio de novos recursos de linguagens, formas de expressão, como os emoticons ${ }^{3}$, memes ${ }^{4}$, imagens diversas. Os cidadãos, pelo Tuíter ou outras redes sociais online, cobram das instituições um papel compatível com as expectativas da sociedade. Tais interações auxiliam no processamento cognitivo de muitos

3. Junção das palavras em inglês emotion e icon é muito utilizado para a comunicação de textos em meio eletrônico. É usado para expressar a intenção em um formato gráfico inserido muitas vezes dentro do contexto de um texto escrito.

4. Termo bastante conhecido e utilizado no "mundo da internet", referindo-se ao fenômeno de "viralização"de uma informação, ou seja,qualquer vídeo, imagem, frase, ideia, música que se espalhe entre vários usuários rapidamente, alcançando muita popularidade. 
dos assuntos públicos que estão em pauta. Também são nesses contextos informais de conversação cotidiana que as mensagens veiculadas pela mídia capitalista ${ }^{5}$ são ressignificadas, trazendo à tona novas interpretações e representações da realidade (Marques, 2006). O fato é que há novas configurações de comunicação na esfera pública na contemporaneidade (Levy \& Lemos, 2010; Felice 2014).

Assim, as discussões sobre as deliberações dos atores sociais devem ser retomadas sob o impacto das tecnologias da informação e comunicação que modificaram as condições espaçotemporais e a forma como os cidadãos se relacionam entre si e com as instituições: imprensa, Estado, organizações privadas e públicas (Gomes, 2004, 2005). É nessa perspectiva que analisamos os movimentos de protesto que aconteceram em 2016.

\section{Auditando os dados}

Os homens foram maioria na rede digital, representando $54 \%$ da amostra, não tendo sido possível delimitar a faixa etária. As mulheres representaram 30\%, e 17\% ficaram na categoria outros (empresas, blogs, imprensa, políticos). É importante ressaltar que a identificação dos atores é ainda difusa e difícil, mesmo sendo feita uma a uma.

No total, dos dados analisados, $22 \%$ dos atores sociais se manifestaram a favor do governo, ou seja, uma minoria, e $72 \%$ contra, os demais foram classificados como neutros ou na categoria outros. Embora haja pulverização dos participantes por diversas partes do País, incluindo, inclusive, atores de outras partes do mundo (8\%), percebemos que a grande concentração do debate girou em torno da região Sudeste e, em menor escala, na sequência, Centro-Oeste e Nordeste. Os estados que demonstraram atores mais participativos foram São Paulo, Rio de Janeiro e Minas Gerais, respectivamente.

No tocante à questão da violência, foram encontradas 97 postagens, ou 38\% do total da amostra, com manifestações que consideramos estar alinhadas a algum discurso que imprime violência a outrem ou que relata fato violento ocorrido nas manifestações. Não entraremos a fundo no conceito de violência, pois evidentemente não é o objetivo primeiro desse artigo. Mas, a fim de que possamos avançar em nossas ponderações cabe observar o que entendemos por tal questão.

O dicionário Aurélio nos traz como definição de violência: ato violento; veemência; abuso da força; tirania; opressão; constrangimento exercido sobre alguma pessoa para obrigá-la a fazer um ato qualquer; coação. Tanto o dicionário, quanto muitos autores clássicos concebem a violência como algo do campo da coação. Há uma violência, entretanto, que opera no campo simbólico, construída por maneiras de ver e pensar e que é definida por Bordieu como "uma violência que se exerce com a cumplicidade tácita daqueles que a sofrem e também, frequentemente, daqueles que a exercem na medida em que uns e outros são inconscientes de a exercer ou a sofrer" (Bordieu, 1996, p.16). Essa nos parece ter sido a maior forma de violência presente nas postagens que encontramos no Tuíter durante os protestos.

5. Mídia Capitalista é um conceito usado por Fuchs (2015) para designar as "empresas que são privadas, pertencentes a indivíduos, famílias ou acionistas. Está culturalmente localizada na esfera pública, mas, ao mesmo tempo, faz parte da economia capitalista, e, assim, não só produz informação pública, mas lucro monetário e financeiro ao vender audiência/usuários e/ou conteúdo" (Fuchs, 2015, p.24). 
Os posts não trouxeram relatos relevantes de experiências decorrentes de fatos ocorridos nas ruas. Reportaram-se à violência simbólica muito mais do que à violência observada nos espaços públicos, ou seja, aquela ocasionada por atos policiais ou desentendimentos entre manifestantes. Há, evidentemente, reportes, como no caso abaixo, e que foi amplamente retuitado entre os internautas, de uma cidadã que jogou um veículo sobre manifestantes. Tal episódio ganhou muita repercussão na rede:


Imagem 1. Mulher joga carro em manifestante Fonte: Tuíter G1 - São Paulo

A maior parte dos posts, entretanto, abordou essencialmente: ofensas contra políticos das duas vertentes, esquerda e direita, especialmente PT e PSDB (muito tratado como partido dos coxinhas ${ }^{6}$ ); agressões à rede Globo de Televisão (que foi muito referenciada como GloboGolpista, inclusive por meio de uma hashtag que ganhou grandes proporções no Tuíter); críticas ao sistema (como o post que repercutiu criticamente uma foto postada pelo portal de notícias G1, em que manifestantes tiravam foto com a polícia); e insultos à própria presidente, havendo, inclusive, memes ofensivos à ex-presidente, para citar as principais manifestações.

6. Coxinha é uma alusão pejorativa aos aliados do PSDB e expressão que ficou extensiva aos manifestantes contrários ao governo durante as manifestações pelo impeachment. 




No caso acima, a violência mescla-se ao humor, demonstrando que esses dois recursos estiveram, muitas vezes, lado a lado, para manifestar indignação, protesto contra autoridades, e emoções, presentes na rede social online durante os movimentos de protesto.

\section{Humor na rede}

O humor é uma categoria polêmica. Recuero e Soares ressaltam que compreende "toda uma forma de contexto diferenciada para a interação, onde a fala pode ser compreendida a partir de diferentes elementos". Esses elementos seriam "aceitação da ambiguidade, do paradoxo, das múltiplas interpretações da realidade e da incongruência" (Crawford 2003, p. 1420, citado por Recuero \& Soares, 2013 p. 241).

Nos posts analisados, tivemos a presença do humor em 118 dos 250 tuítes observados, ou seja, em $47,2 \%$ da amostragem, o que nos demonstra que a violência esteve menos presente como forma de manifestação entre os atores sociais do que o humor.

Quase metade dos envolvidos no debate no Tuíter usaram de algum recurso de humor para se manifestar na rede durante as movimentações de março de 2016. O humor foi um termômetro das opiniões do que passou na cabeça dos atores sociais. Aliás, o humor, durante os momentos de conturbação na sociedade, costuma ser um sinalizador social. Ele nos dá indicativos substanciais da opinião pública. Além disso, há o reforço, como pudemos observar, de pontos de vista centrais que estão em circulação na mídia capitalista e em outras esferas de debate, como em bares, e nos próprios lares dos cidadãos.

Por outro lado, a manifestação, por meio do humor, pode também trazer um tom crítico e inverter a lógica dos debates propostos pela mídia capitalista, auxiliar a pressionar governos na tomada 
de decisões, e até a derrubar governantes, como no caso do impeachment aqui em análise. Em nossa observação, em muitos momentos, verificamos o humor associado à crítica social e política, exercendo pressão social, como na imagem abaixo, em que o post trazia o seguinte conteúdo:



Imagem 3. Post crítico à Globo

Fonte: Tuíter Brasil de luto!

No post em análise, os manifestantes da imagem propagada nas redes são acusados de golpistas, por quererem a saída de uma governante legitimamente eleita pelo povo, além de serem ironizados e ridicularizados por beberem champanhe durante os protestos. A crítica estende-se, ainda que em tom de ironia, ao fato de que os fotografados estariam aliados à orquestração da Rede Globo ${ }^{7}$ (“\#globogolpista") para a derrubada da presidente Dilma.

Ainda no tocante ao humor, um dos posts que foi muito comentado e compartilhado foi o que trazia uma imagem de um pedalinho, levado à paulista, e que trazia os seguintes dizeres: "RT revistavoto: Manifestantes levam 'pedalinho' para a \#Paulista como protesto". Entretanto, observamos o post em dois momentos: um postado pelo $\mathrm{G} 1$, um dos principais portais de notícia brasileiros, pertencente às Organizações Globo, e outro, contendo a mesma imagem, postada por outro ator social, também proveniente da mídia, como demonstramos a seguir.

7. A Rede Globo de televisão, emissora mais representativa em audiência do Brasil, foi acusada durante os protestos de estar motivando os protestos e a derrubada da expresidente Dilma Rousseff. Daí surge o rótulo, memes e críticas à emissora, que mereceu o título de \#globogolpista. 


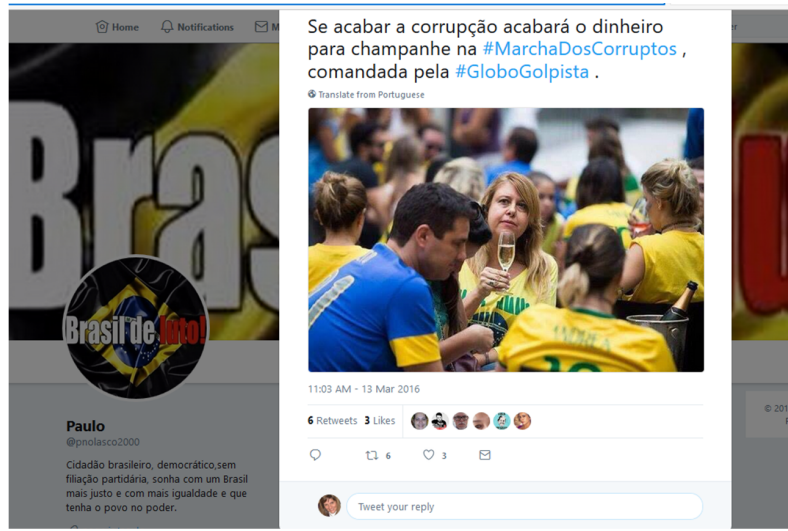

Imagem 4. Protesto com pedalinho na Paulista Fonte: Tuíter G1 - São Paulo
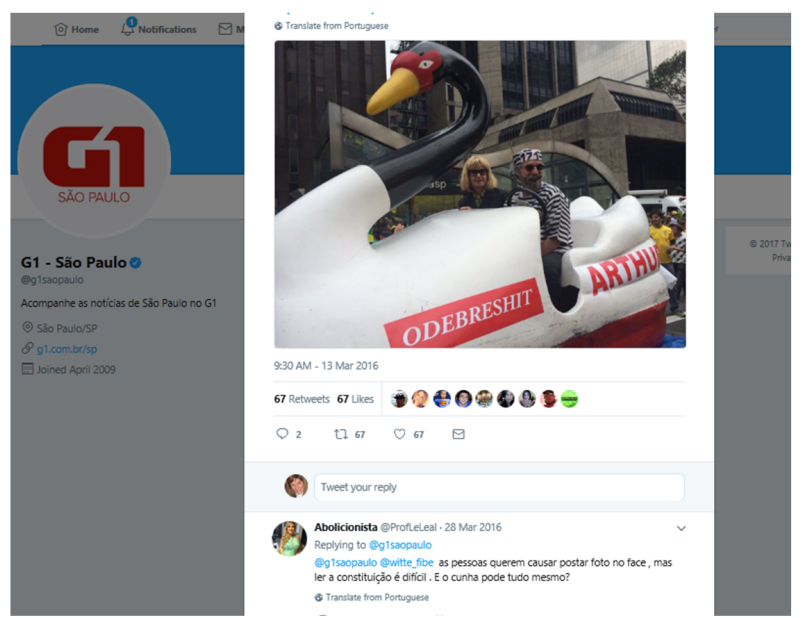

Imagem 4. Protesto com pedalinho na Paulista Fonte: Tuíter G1 - São Paulo 


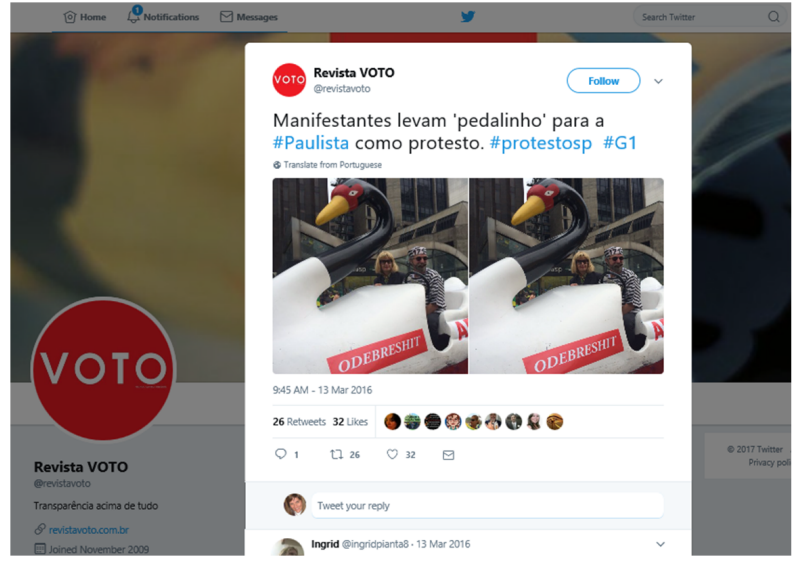

Imagem 5. Protesto com pedalinho na Paulista

Fonte: Tuíter Revista VOTO

Observamos que, ainda que na postagem do G1 haja maior compartilhamento e retuítes, mostrando a credibilidade dada aos grandes grupos de mídia, em ambos os posts não há comentários expressivos. Ou seja, há uma diferença em termos da credibilidade dada ao post da mídia capitalista. Entretanto, o debate por parte dos atores sociais, decorrente da postagem do G1, não avança no sentido de um processo participativo, que integre visões, agregue opiniões, reelabore e aprofunde os sentidos. Essa perspectiva na rede social online ainda é muito reduzida.

Podemos fazer uma inferência de que isso seria decorrente do fato de estarmos diante de uma opinião pública pouco politizada, com um nível educacional que ainda não permite o aprofundamento do debate, como proposto por Gomes (2005). Entretanto, para podermos chegar a dados mais concretos, necessitaríamos aprofundar nossas pesquisas em torno do debate proposto nessa direção.

\section{Considerações finais}

Ainda que as tecnologias da informação e comunicação sejam fundamentais para a forma como se processa a deliberação durante os movimentos sociais contemporâneos, ela não é determinante, sendo um fato material. Percebemos que a comunicação é decorrente de relações mais complexas, com dimensões simbólicas.

No caso em estudo, os atores sociais demonstraram que o uso do humor na rede digital foi, muitas vezes, uma forma de travestir a violência. Essa forma de manifestação caracterizou-se por um tipo de discurso híbrido, que associou um humor ácido, que permitiu desabafos que, muito provavelmente, sem o aparato tecnológico, associado ao uso da linguagem humorística, não teria sido feito por muitos dos atores sociais.

O humor esteve mais presente no debate dos atores sociais do que a violência. A violência encontrada nas postagens não foi a relatada e decorrente de atos policiais, ou eventos ocorridos 
nos protestos, nas ruas. Foi a proveniente dos próprios discursos dos atores sociais contra políticos, partidos, pessoas e instituições diversas.

\section{Bibliografia}

(2017, maio 29). Operação Lava Jato. Folha de São Paulo. Recuperado de http://arte.folha.uol.co m.br/poder/operacao-lava-jato/.

(2017, fevereiro 27). Significado de violência. Dicionário do Aurélio. Recuperado de https://dicio nariodoaurelio.com/violência.

(2016, janeiro 9). Querol, Ricardo. Zygmunt Bauman: As redes sociais são uma armadilha. El País. Recuperado de https://brasil.elpais.com/brasil/2015/12/30/cultura/1451504427_67588 5.html.

Bardin, L. (2010). Análise de conteúdo. Lisboa: Edições 70.

Batista, L. (2016, março 11). Cronologia: protestos 2015 a 2016. Recuperado de http://acervo.est adao.com.br/noticias/acervo,cronologia-protestos-2015-a-2016,12157,0.htm.

Castells, M. (2013). Redes de indignação e esperança: movimentos sociais na era da internet. 1. ed. Rio de Janeiro: Zahar.

Castells, M. (2015). O poder da comunicação. Paz \& Terra (Grupo Editorial Record).

Di Felice, M. \& Lemos, R. (2014). A vida em rede. Campinas, SP: Papirus.

Freire, P. (1992). Pedagogia da esperança: um reencontro com a pedagogia do oprimido. Rio de Janeiro: Paz e Terra.

Goode, W. \& Hatt, P. K. (1973). Métodos em pesquisa social. São Paulo: Nacional.

Gomes, W. (2004). Transformações da política na era da comunicação de massa. São Paulo: Paulus.

Gomes, W. (2005). Internet e participação política em sociedade democrática. Revista Famecos, (27), 58-78. Porto Alegre: PUC-RS.

Gómez de la Torre, A. E. M. \& Reichert, J. (2011). Projetando a sociedade do futuro: uma reflexão sobre os impactos da globalização e das tecnicidades nos cidadãos. Revista Comunicação e Sociedade, 33(56), 149-171.

Lemos, A. \& Lévy, P. (2010). O futuro da internet: em direção a uma ciberdemocracia planetária. São Paulo: Paulus.

Lopes, M. I. V. (2009). Uma aventura epistemológica. Matrizes, Revista do Programa de PósGraduação em Ciências da Comunicação da Universidade de São Paulo, (2), 143-162. Recuperado de www.matrizes.usp.br/index.php/matrizes/article/viewFile/111/178.

Maia, R. C. M. (2008). A conversação sobre temas políticos em contextos comunicativos do cotidiano. Política e Sociedade, (12).

Marques, F. P. J. A. (2006). Debates políticos na Internet: a perspectiva da conversação civil. Opinião Pública, 12(1). 
Martin-Barbero, J. (2009). Uma aventura epistemológica. Entrevistador: Maria Immacolata Vassalo de Lopes. Matrizes, 2, 143-162.

Martino, L. M. S. (2015). Teoria das mídias digitais: linguagens, ambientes e redes. 2. ed. Petrópolis: Editora Vozes.

Mulher joga carro contra manifestante de vermelho e quase atropela PM na frente da casa do Lula, em SBC \#protestosp. (2016, março 13). Tuíter: g1 saopaulo. Recuperado de https://twitter.co $\mathrm{m} / \mathrm{search}$ ?q=twitter.com\%2FM4eSEn0rzL.

Recuero, R \& Soares, P. (2013).Violência simbólica e redes sociais no facebook: o caso da fanpage "Diva Depressão". Galaxia (São Paulo, Online), (26), 239-254.

São Paulo - Manifestantes levam 'pedalinho' para a Paulista como protesto. \#protestosp. (2016, março 13). Tuíter: g1 saopaulo. Recuperado de https://t.co/OC7aIBXeyi.

Se acabar a corrupção acabará o dinheiro para champanhe na \#MarchaDosCorruptos , comandada pela \#GloboGolpista. (2016, março 13). Tuíter: pnolasco2000. Recuperado de https://twitter. com/pnolasco2000/status/709077544537092097/photo/1.

SP - Pessoas tiram foto com o choque da PM. 'É esse que entra na favela?', perguntou uma manifestante.\#protestosp. (2016, março 13). Comentário neste post. Tuíter: GuilhermeTom. Recuperado de https://twitter.com/g1saopaulo/status/709062222794854401.

Vizer, E. \& Ferreira, J. (2007). Mídia e movimentos sociais - linguagens e coletivos em ação. Paulus. 